\title{
Intersections of Culture, Migration and Intimate Partner Violence as Told by Migrant Youth
}

\author{
David Tokiharu Mayeda ${ }^{1, *}$ and Raagini Vijaykumar ${ }^{2}$ \\ ${ }^{1}$ The University of Auckland, Disciplinary Area of Sociology, New Zealand \\ ${ }^{2}$ The University of Auckland, Sociology and Law, New Zealand
}

\begin{abstract}
Like many other western nations, New Zealand has experienced significant migration since the mid-1980s. According to the most recent census, roughly one out of every four persons living in New Zealand is foreign born. The significant number of migrants to New Zealand of Asian and Middle Eastern ancestries has led to the development of rich and diverse ethnic enclaves. However, young people from these communities experience significant pressures to assimilate into western culture, which sometimes clash with parental desires to perpetuate cultural traditions. Drawing on 10 small group interviews conducted with 11 adolescent and 16 young adult female interviewees of Asian and Middle Eastern backgrounds in Auckland, New Zealand, this study examines how participants traverse culturally prescribed gender roles as they relate to intimate partner violence (IPV). Emergent themes from the study address participants' conceptualization of IPV, processes of learning IPV, and pressures to follow rigid gender-roles tied to IPV that are culturally embedded. The article closes with discussion on interpretation of research findings without perpetuating an Orientalist framework.
\end{abstract}

Keywords: Honor, shame, Orientalism, intimate partner violence, migrant, youth, coercive control.

\section{INTRODUCTION}

In 2004, Fanslow and Robinson published research on New Zealand that exposed the country's serious concerns with intimate partner violence (IPV). Based on a sample of 2,674 women residing in two of New Zealand's major cities, the study found that just over $33 \%$ of those surveyed had experienced physical or sexual violence at the hands of an intimate partner over their lifetime, rates higher than any other country participating in the Organisation for Economic Cooperation and Development (Stuff 2011). While Fanslow and Robinson's work is extremely important, the study was conducted during a time when only $7 \%$ of all women in the sampled area identified as Asian.

Although only 4.2 million people reside in New Zealand, the country boasts a complex and ethnically diverse residency. Historically, New Zealand was colonized by the British. Now considered a settler state, New Zealand's indigenous Maori population only represents $14.5 \%$ of the country's population and does not exercise sovereignty within the country's central political institutions. New Zealand Europeans (commonly referred to as Pakeha) are the country's largest ethnic population while also holding the greatest economic and political power. However, European and non-European migrants continue to alter New Zealand's cultural landscape. By 2013 , over $25 \%$ of

*Address correspondence to this author at The University of Auckland, Disciplinary Area of Sociology, New Zealand; Tel: 6493737599;

Fax: 6493737439; E-mail: d.mayeda@auckland.ac.nz
New Zealand's total population was born overseas. Ethnic groups from diverse Pacific Islands are well represented in the country, though varied Asian groups comprise the fastest growing ethnic minority population, nearly doubling in size from 2001 to 2013 (Statistics New Zealand 2014a).

With a population of approximately 1.4 million residents, Auckland is New Zealand's largest city. Like many global hubs that are destination sites for migrants, Auckland's ethnic demographics are widerranging than the rest of New Zealand. In 2013, 23.1\% of all Auckland residents identified as Asian (Statistics New Zealand 2014b). Born overseas and domestically, Auckland's largest Asian ethnic groups are currently Chinese, Indian, Korean, Filipino and Sri Lankan; though growing at a slower rate than Asians, Middle Easterners represent approximately $1 \%$ of Auckland's population (Auckland Council 2014: 11-12). Emerging information from New Zealand's census also shows that Auckland's Asian populations are considerably younger than the city's total population (Tan 2015), which is relevant in the IPV field since scholarship has demonstrated that adolescence and young adulthood are critical periods when individuals form perceptions of what constitutes a healthy intimate relationship (Fredland et al. 2005; Johnson et al. 2005; Arriaga and Foshee 2004; Smith, White, and Lindsay 2003; Wolfe and Foshee 2003).

Considering Auckland's shifting ethnic and age demographics and high IPV rates, the city is positioned as a useful site internationally to explore how IPV 
materializes and is understood amongst youth from typically under-studied migrant populations. Relying on 10 small group interviews with adolescent girls and young women from predominantly Asian backgrounds, this study will outline how participants conceptualize IPV, where they learn dimensions of IPV, and how elements from their respective cultures interface with IPV within a migrant context. The article will close with discussion on interpreting information on IPV derived from ethnic minority, migrant populations in a responsible manner.

\section{LITERATURE: INTIMATE PARTNER VIOLENCE AMONG MIGRANT POPULATIONS}

A rich body of literature exists covering the challenges that women from migrant backgrounds face with regard to IPV. Because migrant women's lives are simultaneously compounded by factors tied to ethnic minority status, immigration processes, gender inequality and class marginalization, much of the scholarship on migrant women and their experiences with IPV has relied on Crenshaw's (1991: 1252) concept of intersectionality, which argues, "women of color experience racism in ways not always the same as those experienced by men of color and sexism in ways not always parallel to experiences of white women..." Consequently, antiracist and feminist campaigns are limited in their effectiveness if they do not account for or intersect with one another.

Within the body of literature on IPV amongst migrant women, scholarship has pointed out the ways that intersecting factors increase migrant women's isolation and vulnerability. Along with patterns of patriarchy that cut across all ethnic groups, factors contributing to migrant women's vulnerability include precarious residency status, language incompatibility with mainstream services, familial and community-based isolation, and a propensity to think services in the host country are unavailable due to past negative experiences in one's home country (Menjivar and Salcido 2002). Migrant women of Asian and Latina backgrounds in the United States, for example, have stated that once settled in their new environment, economic and social dependence on abusive husbands was especially problematic because newly established social networks in the host country were limited to their husbands' family members and friends (Bauer et al. 2000). Likewise, migrant Vietnamese women in Seattle, Washington (USA) have reported that in Vietnam, "they could at least talk to their neighbors and friends if they were being abused, whereas in the
United States they have no one with whom to confide because of their isolation" (Shiu-Thornton, Senturia, and Sullivan 2005: 967). Along with diminished networks of friends and family, social isolation among migrant women is often furthered in host countries by language barriers and cultural beliefs that stress not expressing problems beyond the family (Ghafournia 2011). Thus, even if migrant women arrive in a new country and live in ethnic enclaves with densely established communication networks, they may still be socially isolated since airing family problems can subject women to stigmatization through rumors and gossip. In short, migrant women's lack of anonymity in tightly connected ethnic communities can make it more difficult for them to seek help due to the combination of (1) not having close friends and family within the community and (2) not wanting to bear a denouncing spotlight that blames them for disrupting family harmony (Lee 2013; Reina, Lohman, and Maldonado 2013).

Legal issues connected to immigration status frequently extend migrant women's vulnerability once ensnared in violent relationships. Many migrant women are unfamiliar with the host country's laws, in particular those surrounding immigration policies - an unfamiliarity which may be exacerbated if migrant women are still learning the host country's dominant language. This is an especially heavy concern for female migrants who are undocumented (Raj and Silverman 2002; Bauer et al. 2000), but even female migrants who enter host countries through statesanctioned channels are subject to threats of deportation due to probationary conditions, a circumstance that reifies male privilege. As Burman and Chantler (2005: 65) argue, immigration laws that make women's residency status contingent upon partnership with a male resident provide "a powerful weapon to the perpetrator's arsenal of tactics of abuse."

The factors outlined above tend to be applicable to migrant women of adult ages who find themselves in abusive marriages. The literature is thinner in addressing adolescent girls and young women from migrant communities who may be in the early stages of exploring intimate relationships. However, research conducted predominantly in Sweden has concentrated on young women and girls from ethnic enclaves where Islam is often practiced (e.g., Kurdish, Turkish, Iraqi, Iranian and Indian communities). The bulk of the literature in this area has called attention to discriminatory patterns of discourse in western media, 
government and education that stigmatize migrant communities by emphasizing cultural constructs of honor, which police young women's and girls' sexuality and result in honor-based violence. Dominant discourses that uncritically present migrant girls as hapless victims negate the agency that many migrant teenage girls exercise. Moreover, when these same dominant narratives present migrant cultures as homogenously patriarchal, anti-immigration sentiments are reified; meanwhile the western host culture is viewed in limited perspective, as unquestionably progressive with respect to gender equity and absent of any patriarchal tendencies (Yurdakul and Korteweg 2013; Gruber 2011; Hellgren and Hobson 2008). Other scholarship coming out of Sweden has added, however, that girls and young women from these migrant communities often struggle with pressures to assimilate when exploring dating relationships, as their families strive to maintain traditional boundaries that prevent intimate partnerships prior to marriage. When girls and young women break away from traditional gender roles, they can find themselves feeling isolated, lonely and vulnerable (Schlytter and Linell 2010; Wikström and Ghazinour 2010). Thus, scholars in the field are faced with the challenge of understanding gender-based violence that is culturally influenced as a particular manifestation of patriarchy without reifying notions of racism.

\section{METHODOLOGY}

In October 2013, the first and second authors met with a non-governmental organization (NGO) based in Auckland, New Zealand that provides domestic violence intervention services for battered women from migrant backgrounds of diverse Asian, Middle Eastern and African ancestries. Taking a community-based participatory research approach (Wallerstein and Duran 2003), researchers worked in collaboration with the NGO to develop a research plan aimed at assisting in development of a continuum of youth services. Following Schulz and colleagues' (2003) work with African American female health workers in Detroit, Michigan (USA), researchers worked in tandem with key personnel from the NGO to develop research instruments and procedures, recruit research participants, participate in community outreach events, apply for grant applications that built organisational capacity and present preliminary research results.

Data collection began in February 2014 and concluded in August the same year. The first and second author interviewed young adult women and adolescent girls from migrant communities of color across the greater Auckland area. With respect to the adult sample, potential participants had to be $(A)$ of Asian, Middle Eastern or African ancestry, (B) between the ages of 18 and 28, and (C) familiar with the partnering NGO. On one end of the spectrum, familiarity with the NGO could simply mean having attended one of the organization's workshops or knowing of the NGO through personal or professional networks. At the other end of the spectrum, familiarity could mean being a current or past client. Using organizational contact lists, NGO staff and the second author invited young adult women via e-mail and over the phone to participate in research concerning IPV within their ethnic communities. As individuals expressed interest in participating, they were scheduled to complete a brief questionnaire and partake in a 1-time small group discussion. Adult discussions took place at The University of Auckland, the NGO's administrative offices and one of the NGO's safe houses.

In addition to the young adult sample, adolescents (ages 16 to 17) attending a local public high school were surveyed and interviewed. Per school administration request, recruitment procedures for the adolescent sample involved recruiting students who fit the study's ethnic demographics (Asian, Middle Eastern or African) through the school's peer mentors programme. High school participants completed the same survey and were asked the same discussion questions as young adult participants. Survey administration and group discussions took place on the school campus during times outside of regular class hours (this paper will only report data from small group discussions). For both the young adult and adolescent samples, the research team attempted to recruit male participants. Unfortunately, only three young adult males responded to study requests; considering the poor response rate by males, male input is not included in analyses. Having adolescent and young adult research participants does spread the study sample's age range over a considerable number of years. However, other scholarship has examined youth violence across wide age ranges, for instance from childhood to age 24 (Dahlberg and Potter 2001). Furthermore, this methodological approach ultimately served as a strength since the research team was able to identify similar themes expressed by research participants from both age cohorts, and it was a deliberate decision on the part of the NGO to interview adolescents and young adults so that opinions could be 
expressed on issues concerning IPV from teenagers who were currently negotiating dating issues, as well as young adults who could reflect upon their recent teenage past. Light food and drinks were provided for all research participants. In all, the study included 16 young adult and 11 adolescent participants. Prior qualitative research on IPV with migrant women of color has included similar sample sizes (Chaudhuri, Morash, and Yingling 2014; Kang 2006; Bui 2003).

Just as participants' age range is broad, so are the study's ethnic demographics. Extensive ethnic diversity exists within each of the "umbrella" ethnic groups that the participating NGO serves - Asian, Middle Eastern and African. Obviously "Asians" are different from "Middle Easterners," who are different from "Africans," and within each of those broad categories are a wide variety of more specific ethnic groups. Still, the NGO is one of the few gender-based violence intervention organizations in New Zealand that specializes in working with these cultural groups and is therefore forced to aid women and children across multiple ethnic backgrounds. This translates to services offered on pan-ethnic levels for women and girls of color from diverse migrant communities. Although these women and girls hold unique cultural characteristics that impact how IPV functions, they also cope with similar forms of gendered discrimination, stemming from both within and beyond their ethnic communities. These connections that cut across ethnicities for women and girls from migrant communities make collectively-based interventions useful (Espiritu 1992). It is with this pan-ethnic perspective that the present research project functions.

Small group discussions consisted of the first and second author and two to four participants. The only exceptions to this included a discussion with two young adult women who were taking refuge in a safe house during the time of interview. For this discussion, the first author was on site to explain the study's purpose and answer potential questions, but was not involved in the discussion because he is male; NGO staff and the research team felt these participants would be more comfortable in discussions strictly with female interviewers given their personal histories as IPV victims and survivors. In two other group discussions, other female student research assistants assisted the second author in facilitating interviews due to logistical conflicts, though the primary author was on site to explain research protocols to participants. All student research assistants underwent training from the lead author and NGO staff in facilitating group discussions on IPV. A counselor with the NGO was on call in case sensitive topics from the discussions warranted such services, though these precautionary measures were never required. Finally, it is noteworthy that both authors are of Asian ancestry and that the second author is female within the age range of interviewees, originally from India, but who has lived in Auckland the past thirteen years; in this vein, the second author simultaneously held researcher and peer status with research participants. All discussions took place in English, which was not a concern given participants' ages. Research procedures were approved by The University of Auckland Human Participants Ethics Committee.

Small group conversations with participants covered a wide range of issues, including how participants defined IPV (Tang et al. 2000), how IPV was justified in families and ethnic communities (Yick and Agbayani-Siewert 1997), where young people - males and females - were socialized to accept and enact IPV (Foshee, Bauman, and Fletcher 1999), and how communities and social service agencies could most effectively intervene to prevent IPV in migrant communities of color. Small group discussions have been used in research on IPV with migrant women (Zannettino 2012; Bauer et al. 2000) and were chosen as the medium through which to have discussions so participants would be able to bounce ideas off one another (Kent and Felkenes 1998). Researchers asked participants to speak to these issues from a perspective that accounted for their ethnic and cultural backgrounds, as well as their families' migrant histories. Discussions were generally free flowing as participants expressed observations that they had made of others within their ethnic communities, and in many cases that they had experienced personally. With participants' permission, group discussions were audio recorded and transcribed verbatim predominantly by the second author. The second author also cleaned transcriptions by re-listening to each discussion while reading the corresponding transcription and making corrections. From there, the first and second author took a grounded theory approach to data analysis, identifying emergent themes within the established topical areas (Bryant and Charmaz 2007; Huberman and Miles 2002; Berg 1998). This method entailed both authors reading through each transcription independently to identify key topics and attendant quotes. From there, the authors discussed how frequently topics were raised by participants, the depth that participants spoke to various topics, and how 
emergent topics connected with existing academic literature. The following three themes were identified out of this process: (1) shifting understandings of IPV; (2) IPV as learned behaviour; and (3) self-sacrifice, shame and family honor. These three themes will be discussed within a framework that balances the influences culture, migration and gender have on adolescent girls and young adult women from migrant backgrounds.

\section{RESULTS}

As presented in Table 1, a total of 27 participants partook in the study. Participants who identified as Indian or Fiji-Indian (of Indian ethnicity but born and raised in Fiji) are over-represented in the sample. Other Asian groups represented in the sample include participants who identified as Chinese, Korean,

Table 1: Descriptive Statistics

\begin{tabular}{|c|c|}
\hline Ethnicity & \# Participants \\
\hline Indian & 10 \\
\hline Fiji-Indian & 4 \\
\hline Chinese & 3 \\
\hline Korean & 3 \\
\hline Chinese/Indian & 2 \\
\hline Pakistani & 2 \\
\hline Afghani & 1 \\
\hline Iranian & 1 \\
\hline Sri Lankan & 1 \\
\hline \multicolumn{2}{|l|}{ Age } \\
\hline 16-17 (high school participants) & 11 \\
\hline $18-20$ & 5 \\
\hline $21-23$ & 5 \\
\hline $24-26$ & 4 \\
\hline $27-28$ & 2 \\
\hline \multicolumn{2}{|l|}{ Sexuality } \\
\hline Heterosexual & 22 \\
\hline Not sure & 4 \\
\hline Intersex & 1 \\
\hline \multicolumn{2}{|c|}{ Current/Former NGO Employee/Volunteer } \\
\hline No & 21 \\
\hline Yes & 6 \\
\hline \multicolumn{2}{|l|}{ Current/Former NGO Client } \\
\hline No & 22 \\
\hline Yes & 5 \\
\hline \multicolumn{2}{|c|}{ Permanent Resident or Citizen of New Zealand } \\
\hline Yes & 24 \\
\hline No & 3 \\
\hline Total & 27 \\
\hline
\end{tabular}

Pakistani and Sri Lankan, and two participants who identified as half Chinese, half Indian. Only two participants identified with Middle Eastern ethnic groups, those being Afghani and Iranian. Unfortunately, no participants of any African backgrounds were included in the study. A majority of the participants were young adults, most of whom fell between the ages of 18 and 23 , while 11 of the participants comprised the high school sample. Finally, a majority of the participants expressed being heterosexual, without a formal affiliation to the participating NGO, and with permanent residency or citizenship to New Zealand.

\subsection{Shifting Understandings of IPV}

It is not unusual for men and women or people from different age groups to construct varying definitions of violence (Larsson and Hill 2013; Tang et al. 2000). Consonant with the literature, after being asked to describe a violent (or non-violent) intimate relationship, participants offered an assortment of responses which elucidated how understandings of violence in intimate relationships shifted with age. When asked how violence emanated in intimate partnerships, participants still in high school spoke with strongest conviction of physical violence. For instance an Indian high school participant in one group stated, "Mostly in Indian communities, I have noticed in my friends and families that usually it is shown through hitting a lot, by using stuff to hit them, like say a shoe..." Still, many of these students, once more engaged in discusion, acknowledged the violent potential of verbal aggression. A discussion between two high school students from a different group illustrated how perceptions of IPV extended beyond physicality to include verbal put downs:

Indian participant: When someone in the relationship first takes a fist, like you know ready to push that person or something. Say, maybe it's a guy in the relationship and he pushes the girl, then you can understand that it is more than just a verbal fight that is happening.

Researcher: So it has to have some physical aspect to it?

Indian participant: Yeah, otherwise it is kind of hard to know.

Chinese participant: I think it is also when they start throwing insults at each other, 
because it is just to hurt the other person, not because they want to help them. It's just they are feeling spiteful.

As demonstrated in the above example, through conversation with one another, high school participants pushed the discussion, asserting that IPV could involve both physical and verbal harm, though participants consistently felt that most of their peers would limit understandings of IPV to physical altercations.

Culture was raised occassionaly as a related factor when teasing out manifestations of physical and verbal IPV. Still, conversations did not significantly connect IPV with cultural norms until participants began discussing more ambiguous measurements of IPV, namely issues surrounding control and intentionality. Stark (2012) explains that within intimate relationships, those with masculine privilege can more easily exert coercive control. This includes a range of offenses, which may be viewed formally as criminal (e.g., stalking). However, most actions that fall under a coercive control framework do not carry legal status within an intimate relationship context even though they perpetuate women's vulnerability and victimization. Behaviors that reflect one intimate partner's coercive control over another include strict oversight and supervision over "commonplace activities of daily living, particularly those associated with women's default roles as mothers, homemakers, and sexual partners, and run the gamut from their access to food, and transport to how they dress, clean, cook, or perform sexually" (Stark 2012: 201).

High school and young adult participants frequently spoke of peers groups, in which male intimate partners would restrict girlfriends' social networks. An Indian high school student stated, "some guys don't want their girlfriend...they don't let them see their friends or be with them as much. They like to take them away from their friendship group, like you have to be with the guy all the time." Likewise, a Korean young adult participant stated it was not uncommon for boyfriends to restrict their girlfriends from going "out to town or something with their friends and things like that, or even not letting them hang out with guy friends." Participants added that these forms of coercive control were designed to cultivate feminine dependence, where a boyfriend becomes "the only person you can turn to and that just makes you more reliant on him" (Chinese high school participant).

Discussions speaking to coercive control led to further conversations about culturally-based male privilege and intentionality within initmate relationships. One high school student, of Indian ethnicity, stated that violence in intimate relationships existed any time one partner purposefully harmed the other, adding, "even if they didn't do it on purpose, if they are trying to justify themselves," violence still exists as an element in the intimate relationship. Young adult participants provided more clarity in extrapolating how patriarchal cultural mores sometimes facilitated male behaviors that could be defined as violent even though males may not be conscious of those behaviors' problematic aspects. A Pakistani participant from the young adult cohort provided an example, stating that once in an intimate relationship some young men would expect their female partner to engage in sexual activities at his will, even if the female partner was not ready: "They think that it is their right as your partner...they wouldn't classify that as violence." Another young adult participant who identified as Fiji-Indian explained that some men fail to realize how certain actions influence their partners in harmful ways because their culture has taught them to endorse a male sense of entitlement. In such cases, control over girlfriends by restricting freedom of movement, limiting social networks, and making expectations around sexual intimacy were perceived as normal components of a romantic relationship, leading some males to commit acts of violence against their female partners without defining their behavior as violent.

Young adult participants also discussed how cultural norms could influence family living arrangements that facilitated some women's abuse. The young adult participants taking refuge in a safe house, both of Fiji-Indian background, explained that they were forced to live with their respective husbands and his parents, who were abusive. One of the women, although not physically struck by her husband or inlaws, was "mentally tortured and emotionally hurt" over extended periods, namely by her mother-in-law who starved her and accused her of making sexual advances towards her father-in-law. The other participant explained that while her husband abused her physically, her in-laws ignored her appeals for help and "were there to back him up every time," a demonstration of violence in itself. Prior research with South Asian migrant communities has explored a trend among mothers of husbands who abuse their daughters-in-law (Raj et al. 2006), noting that these women often times experienced violence when they were younger in a similar context but have earned their way to a place of authority within the family and thus 
feel it is appropriate to perpetuate this form of patriarchal violence against the new female entrant into the family (Kandiyoti 1987). When extended family members accuse young women of infidelity, constrain eating patterns and refrain from helping victims, they are engaging in culturally influenced forms of coercive control that may not register as violence, especially for teenagers who are more prone to view IPV through overt physical and verbal actions. In contrast, young adult participants were more aware of the ways that cultural expectations within the family could contribute to abusive control over women, a theme that will be explored further in the discussion on family honor and shame.

\subsection{IPV as Learned Behaviour}

Although young adult participants expressed broader understandings of IPV than high school participants, interviewees from both cohorts were quick to describe how young people within their communities learned to normalize women's subservience and men's privilege in similar fashion. To be clear, many participants asserted that gender equity existed within their families. Numerous participants made it a point to mention that their mothers were highly educated, worked, and exerted power within the family, that their fathers were supportive of these family dynamics, and that family violence was not present within their households. Nevertheless, participants also spoke extensively of the ways that patriarchy was preserved within sectors of their ethnic communities. When asked how some youth acquired values that normalized men's violence against women, participants stated that learning IPV began with expectations around women's domesticity. For instance, a young adult participant of Sri Lankan ethnicity stated:

There is an expectation in the household that women do all the chores and stuff which is what I am battling with my dad at the moment. But I see that as an example of controlling behavior that we all sort of accept, you know women do all the housework and men sit around being lazy.

To this end, learning IPV was said to be a lifelong learning process, which began with observations of gender and age hierarchies within the culture that molded patriarchal power inequalities.

Assigned with expectations to cook, clean and engage in other household duties that supported men, women and girls were often said to be designated secondary familial status. Participants made connections between women's ascribed status as homemakers and their potential to be victimized. Labelled with subordinate familial status, it became easier for male household members to enact violence upon women if they did not fulfill their assigned domestic obligations. As one Indian high school participant stated, "...women have to look after everything, so if they do something wrong, the husband just hits her... If she cooks the curry and it doesn't taste right, that's what happens. I have seen it." Witnessing IPV transpire in this manner was said to be the foundation upon which boys and girls learned to accept gender-based violence. As a Pakistani young adult participant affirmed:

I have seen young boys imitate the behaviours of other men in the family. A man verbally abuses, and he (the male child) is going to grow up and be like that. And then he takes it out on his sister as well.

It is important to contextualize these research findings within a migrant social environment. Although these types of patriarchal patterns exist in all cultures, they can become stronger in migrant communities when family members are looking for ways to retain their culture of origin within a dominant culture that exerts racial discrimination and compels ethnic communities to shed traditional values. Within this minority-majority context, women's and girls' oppression can become a marker of resistance to cultural assimilation; upholding patriarchy becomes a method by which some migrant community members differentiate themselves from the mainstream host culture (Akipinar 2003).

Though family was a starting point where young people learned to accept and justify IPV, media was noted as a significant auxillary institution that reified patriarchal values as youth grew into adolescence and young adulthood. Participants from multiple discussions expressed dissatisfaction with women's objectification in music, music videos, advertising, television and film, which taught males to value women and girls primarily through unrealistic and derogatory sexualized criteria, and compelled girls to conform to such standards. An Indian young adult participant said, "...with the youth, there's video clips that are really popular like songs that say ho's and bitches, and the way they treat women...can be an influence on younger 
people." Women's sexualization and objectification in the media was said to be a more obvious concern, but participants went on to state that media also swayed youth to equate some forms of IPV with love.

After an Indian high school participant explained how girls get "blinded" by mainstream romantic movies that glorify unrealistic "fairy tale ending[s]," a Chinese high school participant added that in contemporary ethnic media, deceptive narratives exist which persuade girls to view abusive interactions between romantic partners as signs of caring and love:

I know that in lots of Korean dramas, it's always like the girl, and this really rebellious guy, and she always makes him better, and they have this happy ending. But it is so prominent in almost every Korean drama that I think girls are deceived into thinking that it is true when it is actually just abuse.

Numerous participants from both cohorts added that in mainstream and ethnic media, plot lines frequently present men's aggression towards women as signs of love: "Even our own Bollywood movies, there [are] a lot of scenes where rape is okay" (Pakistani young adult participant). Complicating matters further, participants added that mainstream western media functioned correspondingly. An Indian high school participant, for example, made an insightful evaluation of the Twilight book and film series, pointing out that the protagonists' romantic relationship glorifies controlling violence and adversely manipulates youthful perspective: "People look at books like Twilight, and I don't hate it because of the story. I hate it because it is an abusive relationship."

This section has presented the social forces that can normalize IPV among migrant youth. The socialization process begins with family norms which perpetuate strict gender binaries. In turn, women's subordination accelerates their victimization when they fail to meet ascribed feminine expectations around domestic/family obligations. This dynamic, however, is often bolstered when migrant communities face racial discrimination in the host culture and search for ways to maintain their culture of origin. In some cases this is accomplished by emphasizing masculine dominance, an alleged symbol of resistance to western feminist liberation. As will be extrapolated in the following section, discourses that uncritically present western societies as free from male violence and migrant cultures as disproportionately patriarchal are highly problematic. Neverthelss, participants in this study felt it was important to note that within their ethnic communities youth observed cultural traditions perpetuating women's subervience and victimization. This learning process was extended as youth grew into adolescence and began consuming media - both mainstream western media and ethnic media - that glorified young males' aggression directed towards intimate partners. In making these observations within the family and later through media, male youth learned that it was acceptable to enact violence against women, and female youth learned to endure being victimized.

\subsection{Self-Sacrifice, Shame and Family Honor}

In their study with Vietnamese survivors of domestic violence in the United States, Shiu-Thornton, Senturia and Sullivan (2005) state that participants in their study experienced a cultural expectation termed the "silent endurance." Likewise, participants in this study scrutinized a socialization process which stressed that girls' entire lives revolve around attending to their families. Prior to marriage, this entailed caring for younger siblings and older family members; following marriage, participants could expect to care for husbands and their families. In other words, girls and young women were often taught to subscribe to inflexible, selfless notions of femininity, which would ostensibly enhance their chances of securing marriage. As stated by a Pakistani young adult participant, "their whole life, all they have been taught to do is make sure you are gettng ready to get married and have kids. You have no life. Your life is with your husband."

In many non-western, collective cultures, marriage is not simply the unification of two individuals. Rather, it symbolizes a bonding of families. "In this context, shame and guilt attain a different meaning whereby the failures of the individual result in the 'loss of face' or loss of honor for the entire family" (Abraham 2000: 19). Participants from all ethnic groups in this study expressed varying levels of dissatisfaction that girls and women in their cultures were socialized to show deference to males, as well as to women who exercised levels of patriarchal power (e.g., mothers-inlaw). Amongst participants from Indian, Fiji-Indian, Pakistani, Sri Lankan, Afghani and Iranian ethnicities in this study, cultural notions of honor and shame also shaped feminine expectations of self-sacrifice, an issue that study participants from these ethnic backgronds raised independently. When explaining how IPV was 
sustained in her community, an Afghani young adult participant stated:

Shame and dishonor to family is the biggest thing in my culture, which is why unmarried girls have to be so careful. And married women have to be so careful too, not only for the husband's name, but the husband's family.

Many scholars use the term honor-based violence (HBV) to discuss the ways that cultural notions of honor and shame influence IPV in certain Asian and Middle Eastern communities. Gill and colleagues (2012: 75) state that HBV "can be defined as comprising any form of violence perpetrated against women that is associated with patriarchal family, community or other social structures in which the main justification for the violence is the protection of a social construction of honour." As the Afghani participant suggests at the end of the above quote, family honor is connected most tightly to the family patriarch - the father, or as she describes it, "the husband's family." Under the honor/shame system, a father's family honor is most commonly lost (i.e., shamed) when a female family member breaks cultural codes that restrict feminine sexuality. More specifically, for girls or young women who are unmarried, any behaviors associated with premarital sex are considered forbidden; for married women, behaviors signifying infidelity bring familial shame. A family's masculine honor is restored after the offending individual(s) has been punished.

Consequently, adolescent girls and young women from migrant backgrounds sometimes find themselves negotiating parental and broader familial regulations that police their sexuality. In one group discussion, an Iranian young adult participant stated that if she socializes with friends in town at night, her mother will say to her, "Please don't do anything that will ruin your dad's name." The participant went on to explain that being unmarried, the biggest disgrace to her family would be if others in her community suspected she was having sex or worse yet, became pregnant. Following this participant's statement, an Indian young adult participant in the same group quickly added, "That's the same as our culture as well...if you are walking around with a boy, your parents are just like, 'You can't be seen with a boy. Indian aunties will go tell everyone"'.

With respect to how this affected adolescent girls and young women from these migrant backgrounds, participants said boyfriends could use familial notions of honor and shame to manipulate relationships, operating as forms of coercive control. For instance, the Iranian participant described a couple in her peer group whose relationship was violent; the male would coerce his partner to stay in the relationship by saying if she broke up with him, he would show digital pictures of the couple to her parents. Because dating anyone would bring shame to her father's name, the female partner was hiding the relationship from her parents and wider family. A clear example of coerce control, simple pictures of the couple functioned sufficiently as a threat and kept her from exiting the violent relationship.

Likewise, participants stated that the honor/shame system prevented married women in violent relationships from reporting their abuse. After being asked why young women who are being battered by husbands do not seek help from friends, family or law enforcement, one of the Fiji-Indian participants taking refuge in a safe house responded:

I think one of the reasons they don't do it is because they feel like they might bring shame to the family or they might not keep the family honor. It's always the women will be blamed if they lose respect or honor. It's all about respect when it comes to Indian cultures.

When families' reputations are tied so tightly to marital commitments and firm contructs of women's sexual purity, young women ensared in violent relationships lack viable options for support, particularly if support systems in schools, state agencies, and law enforcement are unfamiliar with the cultural customs that sometimes impact these women's and girls' lives. Unfortunately, women's vulnerability is increased when men know how to manipulate honor and shame systems as a culturally driven type of coercive control.

\section{DISCUSSION}

Already balancing a space between mainstream western culture and their parents' traditional cultures, adolescent girls and young women from migrant communities must also navigate the typical tensions that accompany early romantic relationships. These tensions, however, are frequently accompanied by vague understandings of what constitutes IPV, personal backgrounds where gender inequality and IPV have been taught across multiple settings, and cultural values that make discussion of intimate relationships 
extremely difficult. While participants in this study spoke passionately to these issues, it would be unethical to report such findings without properly contextualizing them.

It is critical to reiterate that although some of the participants in this study directly observed IPV occuring within their families and two particpants were taking refuge in a women's safe house, many other participants spoke of IPV as a concern within their ethnic communities, shaped partly by culture; still, it was not an issue within their immediate households or in their own intimate relationships. In other words, diverse experiences with respect to IPV characterized study participants' histories, and it would be faulty to depict participants' ethnic communities as violently patriarchal. Doing so extends an Orientalist discourse that portrays migrant ethnic communities in a onedimensional, negative light and disregards the high levels of IPV that exist across New Zealand and other western societies (Said 1978). Thus, the challenge for scholars who address IPV and HBV in migrant communities lies in addressing a significant social concern that sometimes holds cultural elements without reifying racism directed against diverse Asian and Middle Eastern migrants (Abu-Lughod 2011).

Findings emergent from this study call for secondary educators in western communities with large Asian and Middle Eastern communities to learn about the issues that girls in these communities may face when considering intimate relationships. Educators must be cognizant not to stamp all students from these communities as living in violently patriarchal environments, but still be prepared to discuss familial traditions that confine girls' sexuality, should those concerns arise. Training for educators must also entail how to discuss confidentiality with girls from these ethnic communities and to be cautious in using familybased interventions, which may unintentionally further girls' vulnerability (Alizadeh, Törnkvist, and Hylander 2011).

Successful dating violence prevention programs have been implemented in high school settings (Alexander et al. 2014; Mulford and Blachman-Demmer 2013; Jaycox et al. 2006). In schools with high populations of students from migrant backgrounds, dating violence prevention programs should be implemented with curricula that deconstructs culturallybased gender inequality, critiques western and ethnic media, and encourages students (female and male) to value women's and girls' independent upward social mobility. If schools demonstrate a strategic commitment to addressing IPV at the youth level and do so in ways that respect differences between and within cultures, significant decreases in IPV amongst migrant youth are possible.

\section{STRENGTHS AND LIMITATIONS}

This study was not without its limitations, the foremost being reliance on a small sample size, an over-sampling of participants from Indian backgrounds, and the absence of participants from any African ethnic groups. Still, it is imporant to note that this study is among the first of its kind internationally that includes a difficult to reach population - youth of diverse Asian and Middle Eastern backgrounds within a western context, discussing topics on IPV. Also significant is that across age and ethnic groups, participants offered highly uniform responses to study questions, suggesting that findings emergent from this study carry meaningful validity. Considering that this study was intended to be small and exploratory, the findings warrant support for further research with a larger number of participants, including greater numbers of youth from diverse Middle Eastern and African ethnicities.

\section{REFERENCES}

Abraham, Margaret. 2000. Speaking the Unspeakable: Marital Violence among South Asian Immigrants in the United States. New Brunswick, New Jersey: Rutgers University Press.

Abu-Lughod, Lila. 2011. "Seductions of 'Honor Crime."' Differences: A Journal of Feminist Cultural Studies 22:17-63. http://dx.doi.org/10.1215/10407391-1218238

Akipinar, Aylin. 2003. "The Honour/shame Complex Revisited: Violence Against Women in the Migrant Context." Women's Studies International Forum 26:425-442. http://dx.doi.org/10.1016/j.wsif.2003.08.001

Alexander, Charlene M., Ashley N. Hutchinson, Kelly M. Clougher, Holly A. Davis, Dustin K. Shepler and Yves Ambroise. 2014. "Adolescent Dating Violence: Application of U.S. Primary Prevention Program in St. Lucia." Journal of Counseling \& Development 92:489-498.

Alizadeh, Venus, Lena Törnkvist and Ingrid Hylander. 2011. "Counselling Teenage Girls on Problems Related to the 'Protection of Family Honour' from the perspective of school nurses and counsellors." Health and Social Care in the Community 19:476-484.

http://dx.doi.org/10.1111/j.1365-2524.2011.00993.x

Arriaga, Ximena B. and Vangie A. Foshee. 2004. "Adolescent Dating Violence: Do Adolescents Follow in Their Friends', or Their Parents', Footsteps?" Journal of Interpersonal Violence 19:162-184 http://dx.doi.org/10.1177/0886260503260247

Auckland Council. 2014. Auckland Profile - Initial Results from the 2013 Census. Auckland: Auckland Council.

Bauer, Heidi M., Michael A. Rodriguez, Seline S. Quiroga and Yvette G. Flores-Ortiz. 2000. "Barriers to Health Care for Abused 
Latina and Asian Immigrant Women." Journal of Health Care for the Poor and Underserved 11:33-44. http://dx.doi.org/10.1353/hpu.2010.0590

Berg, Bruce L. 1998. Qualitative Research Methods in the Social Sciences. Needham Heights, MA: Allyn \& Bacon.

Bryant, Antony and Kathy Charmaz. 2007. The Sage Handbook of Grounded Theory. London: Sage.

Bui, Hoan N. 2003. "Help-seeking Behavior among Abused Immigrant Women: A Case of Vietnamese American Women." Violence Against Women 9:207-239. http://dx.doi.org/10.1177/1077801202239006

Burman, Erica and Khatidja Chantler. 2005. "Domestic Violence and Minoritisation: Legal and Policy Barriers Facing Minoritized Women Leaving Violent Relationships." International Journal of Law and Psychiatry 28:59-74. http://dx.doi.org/10.1016/j.ijlp.2004.12.004

Chaudhuri, Soma, Merry Morash and Julie Yingling. 2014. "Marriage Migration, Patriarchal Bargains, and Wife Abuse: A Study of South Asian Women." Violence Against Women 16:898-920. http://dx.doi.org/10.1177/1077801214521326

Crenshaw, Kimberle. 1991. "Mapping the Margins: Intersectionality, Identity Politics, and Violence against Women of Color." Stanford Law Review 43:1241-1299.

http://dx.doi.org/10.2307/1229039

Dahlberg, Linda L. and Lloyd B. Potter. 2001. "Youth Violence: Developmental Pathways and Prevention Challenges." American Journal of Preventive Medicine 20:3-14. http://dx.doi.org/10.1016/S0749-3797(00)00268-3

Espiritu, Yen Le. 1992. Asian American Panethnicity: Bridging Institutions and Identities. Philadelphia: Temple University Press.

Fanslow, Janet and Elizabeth Robinson. 2004. "Violence Against Women in New Zealand: Prevalence and Health Consequences." The New Zealand Medical Journal 117:212.

Foshee, Vangie A., Karl E. Bauman and G. Fletcher Linder. 1999. "Family Violence and the Perpetration of Adolescent Dating Violence: Examining Social Learning and Social Control Processes." Journal of Marriage and Family 61:331-342. http://dx.doi.org/10.2307/353752

Fredland, Nina M., Izabel B. Ricardo, Jacquelyn C. Campbell, Phyllis W. Sharps, Joan K. Kub and Michael Yonas. 2005. "The Meaning of Dating Violence in the Lives of Middle School Adolescents: A Report of a Focus Group Study." Journal of School Violence 4:95-114. http://dx.doi.org/10.1300/J202v04n02_06

Ghafournia, Nafiseh. 2011. "Battered at Home, Played Down in Policy: Migrant Women and Domestic Violence in Australia." Aggression and Violent Behavior 16:207-213. http://dx.doi.org/10.1016/j.avb.2011.02.009

Gill, Aisha K., Nazand Begikhani and Gill Hague. "Honour'-based Violence in Kurdish Communities." Women's Studies International Forum 35:75-85. http://dx.doi.org/10.1016/j.wsif.2012.02.001

Gruber, Sabine. 2011. "In the Name of Action Against 'Honourrelated' Violence: National Nations, Gender, and Boundaries in the Swedish School's Ambitions to Combat Violence and Oppression." Nordic Journal of Migration Research 1:126136.

http://dx.doi.org/10.2478/v10202-011-0018-9

Hellgren, Zenia and Barbara Hobson. 2008. "Cultural Dialogues in the Good Society: The Case of Honour Killings in Sweden." Ethnicities 8:385-404. http://dx.doi.org/10.1177/1468796808092449

Huberman, Michael A. and Matthew B. Miles. 2002. The Qualitative Researcher's Companion. Thousand Oaks, CA: Sage.

Jaycox, Lisa H., Daniel McCaffrey, Beth Eiseman, Jessica Aronoff, Gene A. Shelley, Rebecca L. Collins and Grant N. Marshall.
2006. "Impact of a School-based Dating Violence Prevention Program among Latino Teens: Randomized Controlled Effectiveness Trial." Journal of Adolescent Health 39:694704.

http://dx.doi.org/10.1016/j.jadohealth.2006.05.002

Johnson, Sara B., Shannon Frattaroli, Jacquelyn Campbell, Joseph Wright, Amari S. Pearosn-Fields and Tina L. Cheng. 2005. "“I Know What Love Means': Gender-Based Violence in the Lives of Urban Adolescents." Journal of Women's Health $14: 172-179$ http://dx.doi.org/10.1089/jwh.2005.14.172

Kandiyoti, Deniz A. 1987. "Emancipated but Unliberated?: Reflections on the Turkish Case." Feminist Studies 13:317338. http://dx.doi.org/10.2307/3177804

Kang, Neelu. 2006. "Women Activists in Indian Diaspora: Making Interventions and Challenging Impediments." South Asia Research 26:145-164. http://dx.doi.org/10.1177/0262728006066489

Kent, Douglas R. and George T. Felkenes. 1998. Cultural Explanations for Vietnamese Youth Involvement in Street Gangs. Westminister, CA: Westminister Police Department, Office of Research and Planning. http://dx.doi.org/10.1037/e309992005-001

Larsson, Paula and Peter Hill. 2013. "Lay Definitions of Violence among Swedish Children, Teenagers, and Adults." Journal of Aggression, Maltreatment \& Trauma 22:282-299. http://dx.doi.org/10.1080/10926771.2013.764954

Lee, Mihan. 2013. "Breaking Barriers: Addressing Structural Obstacles to Social Service Provision for Asian Survivors of Domestic Violence." Violence Against Women 20:1-20. http://dx.doi.org/10.1177/1077801213514486

Menjivar, Cecilia and Olivia Salcido. 2002. "Immigrant Women and Domestic Violence: Common Experiences in Different Countries." Gender \& Society: 16:898-920. http://dx.doi.org/10.1177/089124302237894

Mulford, Carrie F. and Dara R. Blachman-Demner. 2013. "Teen Dating Violence: Building a Research Program through Collaborative Insights." Violence Against Women 19:756770 .

http://dx.doi.org/10.1177/1077801213494705

Raj, Anita, Kaí N. Livramento, M. Christina Santana, Jhumka Gupta and Jay G. Silverman. 2006. "Victims of intimate partner violence more likely to report abuse from in-laws." Violence Against Women 12:936-949. http://dx.doi.org/10.1177/1077801206292935

Raj, Anita and Silverman, Jay. 2002. "Violence Against Immigrant Women: The Roles of Culture, Context, and Legal Immigrant Status on Intimate Partner Violence." Violence Against Women 8:367-398 http://dx.doi.org/10.1177/10778010222183107

Reina, Angelica S., Brenda J. Johman and Marta Maria Maldonado. 2013. "'He Said They'd Deport Me': Factors Influencing Domestic Violence Help-Seeking Practices among Latina Immigrants." Journal of Interpersonal Violence 29:593-615. http://dx.doi.org/10.1177/0886260513505214

Said, Edward. 1978. Orientalism. New York: Vintage Books

Schlytter, Astrid and Hanna Linell. 2010. "Girls with Honour-related Problems in a Comparative Perspective." International Journal of Social Welfare 19:152-161. http://dx.doi.org/10.1111/j.1468-2397.2009.00651.x

Schulz, Amy J., Barbara A. Israel, Edith A. Parker, Murlisa Lockett, Yolanda R. Hill and Rochelle Wills. 2003. "Engaging Women in Community Based Participatory Research for Health: The East Side Village Health Worker Partnership." Pp. 293-315 in Community-Based Participatory Research for Health, edited by M. Minkler, and N. Wallerstain. San Francisco: JosseyBass. 
Shiu-Thornton, Sharyne, Kirsten Senturia and Marianne Sullivan. 2005. "'Like a Bird in a Cage': Vietnamese Women Survivors Talk About Domestic Violence." Journal of Interpersonal Violence 20:959-976. http://dx.doi.org/10.1177/0886260505277677

Smith, Paige Hall, Jacquelyn W. White and Lindsay J. Holland. 2003. "A Longitudinal Perspective on Dating Violence Among Adolescent and College-Age Women." American Journal of Public Health 93:1104-1109. http://dx.doi.org/10.2105/AJPH.93.7.1104

Stark, Evan. 2012. "Looking Beyond Domestic Violence: Policing Coercive Control." Journal of Police Crisis Negotiations 12:199-217. http://dx.doi.org/10.1080/15332586.2012.725016

Statistics New Zealand. 2014a. "Number of overseas-born tops 1 million, 2013 Census shows." April 15. Retrieved 14 September, 2015 (http://www.stats.govt.nz/Census/2013census/profile-and-summary-reports/qstats-culture-identitynz-mr.aspx).

Statistics New Zealand. 2014b. "Half a million Aucklanders born overseas." April 15. Retrieved 14 September, 2015 (www.stats.govt.nz/Census/2013-census/profile-andsummary-reports/qstats-culture-identity-auck-mr.aspx).

Stuff.co.nz. 2011. "NZ worst for domestic violence - UN Report." July 24. Retrieved September 14, 2015. (http://www.stuff.co.nz/ national/5332717/NZ-worst-for-domestic-violence-UN-report).

Tan, Lincoln. 2015. "Asian Auckland: How Our City Has Changed Explore Our Interactive." March 10. Retrieved September 15, $2015 . \quad$ (http://www.nzherald.co.nz/nz/news/article.cfm? c_id=1\&objectid=11414457).

Tang, Catherine So-kum, Day Wong, Fanny M.C Cheung and Antoinette Lee. 2000. "Exploring How Chinese Define
Violence Against Women: A Focus Group Study in Hong Kong." Women's Studies International Forum 23:197-209. http://dx.doi.org/10.1016/S0277-5395(00)00071-6

Wallerstain, Nina and Bonnie Duran. 2003. "The conceptual, historical, and practice of community based participatory research and related participatory traditions." Pp. 27-52 in Community-Based Participatory Research for Health, edited by M. Minkler, and N. Wallerstain. San Francisco: JosseyBass.

Wikström, Eva and Mehdi Ghazinour. 2010. "Swedish Experience of Sheltered Housing and Conflicting Theories in Use with Special Regards to Honour Related Violence (HRV)." European Journal of Social Work 13:245-259. http://dx.doi.org/10.1080/13691451003690981

Wolfe, Kimberly A. and Vangie A. Foshee. 2003. "Family Violence, Anger Expressions Styles, and Adolescent Dating Violence." Journal of Family Violence 18:309-316. http://dx.doi.org/10.1023/A:1026237914406

Yick, Alice G. and Pauline Agbayani-Siewert. 1997. "Perceptions of Domestic Violence in a Chinese American Community." Journal of Interpersonal Violence 12:832-846. http://dx.doi.org/10.1177/088626097012006004

Yurdakul, Gökçe and Anna C. Korteweg. 2013. "Gender Equality and Immigrant Integration: Honor Killing and Forced Marriage Debates in the Netherlands, Germany, and Britain." Women's Studies International Forum 41:204-214. http://dx.doi.org/10.1016/j.wsif.2013.07.011

Zannettino, Lana. 2012. “....There is no war here; it is only the relationship that makes us scared': Factors Having Impact on Domestic Violence in Liberian Refugee Communities in South Australia." Violence Against Women 18:807-828. http://dx.doi.org/10.1177/1077801212455162

DOI: http://dx.doi.org/10.6000/1929-4409.2015.04.21

(C) 2015 Mayeda and Vijaykumar; Licensee Lifescience Global.

This is an open access article licensed under the terms of the Creative Commons Attribution Non-Commercial License (http://creativecommons.org/licenses/by-nc/3.0/) which permits unrestricted, non-commercial use, distribution and reproduction in any medium, provided the work is properly cited. 